\title{
CINEMA IN CONTEXT: HET EINDE VAN FILMSTUDIES?
}

In januari I996 lanceerde filmfanaat en computerfreak Col Needham I M Db.com als commerciële website. Deze site, die de afgelopen tien jaar is uitgegroeid tot een onmisbare bron voor meer dan veertig miljoen filmliefhebbers wereldwijd, ontstond vanuit een persoonlijk archief, of beter: een persoonlijke database. Als geheugensteuntje besloot Needham op 23-jarige leeftijd een inventaris op te maken van de duizend films die hij jaarlijks bekeek. Vrij snel gingen zijn vrienden en kennissen hun persoonlijke databases van acteurs, regisseurs, scenarioschrijvers, plotbeschrijvingen enzovoort, ook beschikbaar stellen en dit groeide uit tot de Internet Movie Database (I M Db). ${ }^{\mathrm{I}}$ In april 2006 zette filmhistoricus Karel Dibbets, werkzaam aan de Universiteit van Amsterdam bij de afdeling Media en Cultuur, zijn database Cinema Context online. Deze database, die voorlopig uitsluitend de Nederlandse filmcultuur dekt, heeft de ambitie om een nieuwe standaard te worden onder de digitale naslagwerken, vergelijkbaar met de ImDb. Maar daar waar de ImDb in de eerste plaats informatie biedt over de productie van de tekst (wie en wat?), leent de database van Dibbets zich hoofdzakelijk als onderzoeksinstrument voor de distributie en vertoning van de tekst (waar en wanneer?). ${ }^{2}$ De online lancering van Cinema Context voltrok zich in het kader van de internationale conferentie 'Cinema in Context: Sharing Histories of Moviegoing', die plaatsvond in Amsterdam op 20 en 2I april 2006. De redactie van het Tijdschrift voor Mediageschiedenis heeft besloten een themanummer aan deze conferentie te wijden, omdat ze de urgente filmhistoriografische vraagstukken die door verschillende sprekers werden opgeworpen wil vastleggen en het voortouw wil nemen in een in haar ogen belangrijk debat over de toekomst en de grenzen van filmstudies. De reikwijdte van dit debat gaat veel verder dan Nederland en zelfs dan Europa. Het is dan ook bijzonder dat de conferentie 'Cinema in Context', medegesponsord door de Vereniging Geschiedenis, Beeld en Geluid, werd gehouden in hartje Amsterdam.

De centrale vraag die de organisatoren van de conferentie stelden in hun programmaboekje was: 'How do we make sense of the expanding universe of digital information?’3 Een vraag die hiermee samenhangt betreft de heterogeniteit van deze digitale informatie: hoe kunnen we digitale bronnen van verschillende aard vergelijken en aan elkaar relateren in één zelfde onderzoek? Of anders gezegd: hoe gaan we binnen ons vakgebied om met dit toenemende aanbod van 
onderling sterk variërende digitale bronnen? Sinds 2004 hebben Europese onderzoekers uit Nederland, België, Frankrijk, Duitsland en Engeland samen met onderzoekers uit Australië ${ }^{4}$ en de Verenigde Staten ${ }^{5}$ hun projecten samengebracht in een nieuw onderzoeksverband, getiteld ном E R (History of Moviegoing, Exhibition and Reception), dat zich concentreert op het elektronisch registreren, ordenen en ontsluiten van data over filmvertoning en -receptie, met name vóór de Tweede Wereldoorlog, en in sommige gevallen zelfs voor I9I4. Home R streeft ernaar alle projecten aan elkaar te koppelen om zo data in het gemeenschappelijke historische onderzoeksveld uit te wisselen. ${ }^{6}$ Op de conferentie 'Cinema in Context' zijn verscheidene Hом E R-projecten gepresenteerd, onder andere de Siegen Databases, het London Project en de Verlichte Stad, die we samen met Cinema Context kort zullen toelichten. Verder waren er ook onder de keynote sprekers twee HоM E R-leden, Richard Maltby (founding member) en Robert C. Allen (fellow traveler).

\section{Presentatie van digitale databases}

Aan de universiteit van Siegen (Duitsland), binnen het onderzoeksproject 'Industrialisiering der Wahrnehmung', is Joseph Garncarz een tweetalige (EngelsDuitse) database over de Duitse filmcultuur tussen I895 en I920 aan het opzetten, die in 2007 online moet gaan. Deze database beslaat drie terreinen, die elk een eigen database vormen: het filmaanbod in Duitsland tot I920, de programmering van Duitse vaste bioscopen tussen I905 en I9I4 en reisbioscopen in Duitsland tussen I896 en I926. De gegevens over het Duitse filmaanbod zijn ontleend aan het werk van Herbert Birett over de in Duitsland vertoonde films, ${ }^{7}$ terwijl voor de data over de reisbioscopen het kermisvakblad Der Komet de centrale bron is. Aangezien veel reisbioscoophouders, zeker in de grensstreek, zich helemaal niet aan grenzen hielden, zou dat voor Nederland een interessante 'Fundgrube' kunnen worden. Daarnaast zouden de drie Siegen Databases, net als eerder al de naslagwerken van Birett, interessant vergelijkingsmateriaal voor onderzoek naar de Nederlandse filmvertoning kunnen bieden, omdat Duitsland net als Nederland in de eerste twee decennia van de filmgeschiedenis veel meer een filmvertonend dan een filmproducerend land was. Wat opvalt bij de Siegen Databases is dat de beschikbaarheid van bronnen de selectie heeft bepaald. Zo is er bij de selectie van de te onderzoeken steden gekeken of de stad een nog steeds bestaande krant als bron kon aanleveren, die een continuïteit in film- en bioscoopadvertenties kon garanderen. Daarbij is gekozen voor negen Duitse steden: drie grote, drie middelgrote en drie kleine steden, waarbij het Westen, het Oosten en het Zuiden zijn vertegenwoordigd en opvallend genoeg de hoofdstad Berlijn ontbreekt. De reden hiervoor is dat Berlijn geen krant heeft die aan bovengenoemde voorwaarden voldoet. Bij het programmeringonderzoek wordt zoveel mogelijk het hele programma vermeld en niet alleen de 
hoofdfilm. Alle filmtitels worden weergegeven zoals ze in advertenties zijn aangetroffen (mogelijk met de vermelding dat in werkelijkheid minder werd vertoond). ${ }^{8}$

Aan de universiteiten van Gent en Antwerpen wordt onder leiding van Daniël Biltereyst en Philippe Meers het onderzoeksproject 'De Verlichte Stad' uitgevoerd. Het betreft een longitudinaal onderzoek, reikend over de periode I895-2004, naar de sociale rol van filmvertoning en -consumptie in Brussel en Vlaanderen, tegen de achtergrond van modernisering en urbanisatie. Het onderzoek omvat drie deelprojecten. Allereerst betreft het een uitgebreide inventarisatie van bioscopen in Vlaanderen, met aandacht voor de geografische distributie en de relaties tussen het commerciële en het verzuilde circuit. Deze bioscopendatabase, die start na de Eerste Wereldoorlog en loopt tot I990, maakt een onderscheid tussen het aantal cinema's enerzijds en het aantal filmdoeken anderzijds. Vervolgens richt men zich op een analyse van de interactie tussen ideologie (met name verzuiling), economie en filmcultuur door een diachroon onderzoek naar bioscopen, vertoning en programmering in grootstedelijke, provinciale en rurale context. Het derde deelproject behelst de analyse van de interactie tussen ideologie, economie en filmconsumptie via historisch publieksonderzoek binnen de ervaring van een cultuur van vrijetijdsbesteding. ${ }^{9}$

Een derde ном в R-project verbonden met een database, die in tegenstelling tot de Siegen Databases en de Verlichte Stad reeds vrijelijk op het net is te consulteren, is het 'London Project', geleid door Ian Christie van Birkbeck College, University of London, en uitgevoerd door onderzoekers Luke McKernan en Simon Brown. ${ }^{\text {Io }}$ Het London Project is tweedelig: het richt zich enerzijds op de 'businesses' of filmbedrijven, waarbij niet alleen gedacht moet worden aan de traditionele bedrijven van filmproductie, -distributie en -vertoning, maar ook aan aanverwante commercie, zoals de chocolade-industrie en stoelreinigingsdiensten; en anderzijds op de 'venues' of vertoningplaatsen, waartoe ook ongewone plekken als kerken en dergelijke worden gerekend. De database van de 'venues' is gelimiteerd tot Londen in de periode I894-I9I4. De bronnen van het London Project zijn divers: vakpers, kranten, overheidsstukken en lokale archiefstukken, de Britse Kamer van Koophandel, maar ook memoires, al dan niet gepubliceerd. McKernan en Brown wisten zelfs historische lijsten te presenteren van beweegredenen van bezoekers om naar de bioscoop te gaan. Ze onderzochten hoe de prijs van een bioscoopkaartje zich verhield tot andere concurrente vrijetijdsbestedingen met de achterliggende vraag: 'How to spend a penny?' Kortom, allemaal bronnen waar je jaloers op kunt zijn maar waar je ook alert bij moet blijven. Een eerste opmerkelijk resultaat van het London Project was dat het trekken van conclusies op basis van aantallen stoelen bij vertoningsplekken bedrieglijk kan zijn. Niet alleen zijn de aantallen die in de door het London Project onderzochte bronnen worden gegeven niet altijd betrouwbaar - er waren ook staanplaatsen, kinderen konden met tweeën in één stoel gepropt worden en bij de veelvuldige doorlopende voorstellingen was het niet altijd duidelijk wie 
nu een nieuwe bezoeker was. Tellen blijft mensenwerk. In ieder geval komt McKernan op het aantal van 383 vaste vertoningsplekken in Londen in I9I4. Overigens was dat in Amsterdam twintig keer minder, maar rond I9ı had Londen dan ook dertien keer zoveel inwoners als onze hoofdstad. ${ }^{\text {II }}$

Temidden van deze Europese projecten, die veelal in wording zijn, bevindt Cinema Context zich niet alleen in goed gezelschap, maar loopt ook aardig op kop. Cinema Context is een combinatie van vier collecties van gegevens die ons informeren over de totstandkoming van een filmvoorstelling: films, bioscopen, personen en bedrijven. Tot nu toe is de focus op de grotere steden, tevens beperkt tot de vooroorlogse periode, maar het is de ambitie om heel Nederland en de volledige twintigste eeuw diachroon en synchroon te omvatten. Aan de basis van Cinema Context ligt Dibbets' persoonlijke database van Nederlandse bioscopen, waarin alle bioscopen die in Nederland hebben bestaan of nog steeds bestaan zijn opgenomen, met daarbij ook gegevens over personen (eigenaren) en rechtspersonen (beheersmaatschappijen e.d.). ${ }^{\text {I2 }}$ Tevens werkte Dibbets voorafgaand aan de lancering van Cinema Context aan de digitale ontsluiting van het archief van de Centrale Filmkeuring (I928-ı977). Beide onderzoeken vormden een belangrijke ondergrond voor de Cinema Context database, die de bioscoopprogrammering als uitgangspunt neemt en deze bekijkt zowel vanuit de distributie- als vanuit de vertoningskant. Indien over de voorstelling data over andere aspecten dan de geprojecteerde film bekend zijn - denk aan live acts of muziek zijn die ook in de database opgenomen. Net als bij de buitenlandse projecten bepaalde de onderzoeksvraag mede de structuur (en content) van de database: Dibbets wil via programmering meer te weten komen over distributie en vertoning van film. Hij is niet zozeer geïnteresseerd in productie, aangezien die gegevens allang zijn ontsloten via I M Db. Evenmin is de Cinema Context database ontwikkeld met het oog op de andere kant van het spectrum, namelijk receptie. Vandaar dat de database zich net als het Siegen-project baseert op krantenadvertenties en niet op krantenrecensies. Dit sluit echter niet uit dat receptie in de toekomst een aanvullend onderzoeksveld wordt, net zoals nu al het geval is bij het onderzoeksproject 'De Verlichte Stad' in België.

\section{Praktische en algemeen-wetenschappelijke vragen}

De presentatie van deze verschillende databases roept allerlei belangrijke vragen op. Allereerst zijn dat vragen van praktische aard. Nadat we hebben kunnen vaststellen dat zowel in Nederland als in het buitenland nog steeds veel onderzoek wordt gedaan naar regionale en lokale filmcultuur, dringt de vraag zich op wat de rol van deze nieuwe digitale instrumenten in dit onderzoek is. Hoe worden deze databases opgesteld? Op grond van welke selectie? Of anders gesteld: Wat komt eerst? De onderzoeksvraag of de database? Dit is een typisch kip-enei-probleem: je hebt namelijk een onderzoeksvraag nodig om een database op te 
stellen, maar een database kan tegelijkertijd nieuwe onderzoeksvragen genereren die weer nieuwe selectiecriteria opleggen. Dus enerzijds betekent een database een beperking: het doel is namelijk om de oorspronkelijke onderzoeksvraag te beantwoorden. Anderzijds kan een database door puur toeval (serendipiteit) tot echte verrassingen leiden en nieuwe vragen oproepen. Zo vertelde Karel Dibbets in zijn conferentiepresentatie dat hij via zijn Cinema Context database toevallig heeft ontdekt dat bij de tien langstlopende films in Nederland tot aan I940 onverwachte toppers zitten, zoals een tot nu toe zelfs ongeïdentificeerde buitenlandse seksuele voorlichtingsfilm, getiteld DE HYG IËNE VAN HET HUWELIJK. Op dezelfde wijze kwam hij ook tot de vaststelling dat sommige Nederlandse geluidsfilms van de jaren dertig als DE JANTJEs bepaald niet onderdeden voor gecanoniseerde Amerikaanse box office hits als de zwijgende versie van BEN HUR. Dit staat haaks op ons verwachtingspatroon en ons underdog-model wat betreft de Nederlandse filmproductie. Het roept nieuwe onderzoeksvragen op als: Kenden andere Europese landen juist met de komst van de geluidsfilm ook dergelijke populaire nationale producties die zich in eigen land konden meten met de Amerikaanse kaskrakers? Was die voorlichtingsfilm elders ook zo geliefd? Of hadden andere Europese landen juist weer andere uitschieters?

Aan de basis van elke database ligt dus een onderzoeksvraag die bepaalt wat we erin steken. Maar daaraan gekoppeld is ook de vraag: Wat halen we eruit? Of beter: Hoe halen we het eruit? Hoe lezen we onze resultaten? Zoals Richard Maltby opperde tijdens de slotconclusie van de conferentie: 'Zullen de geesteswetenschappers zich moeten gaan verdiepen in een vak als statistiek en zou dat wellicht een verplichte cursus moeten worden in filmwetenschappelijke opleidingen?' En als de databases steeds complexer worden moeten we ongetwijfeld het spoor van Tom Cruise in MINORITY REPORT (2002) volgen en speciale touch screen vaardigheden ontwikkelen. ${ }^{\text {I3 }}$

Tom Cruise (l) in MINORITY REPORT (2002). Bron: 20th Century Fox

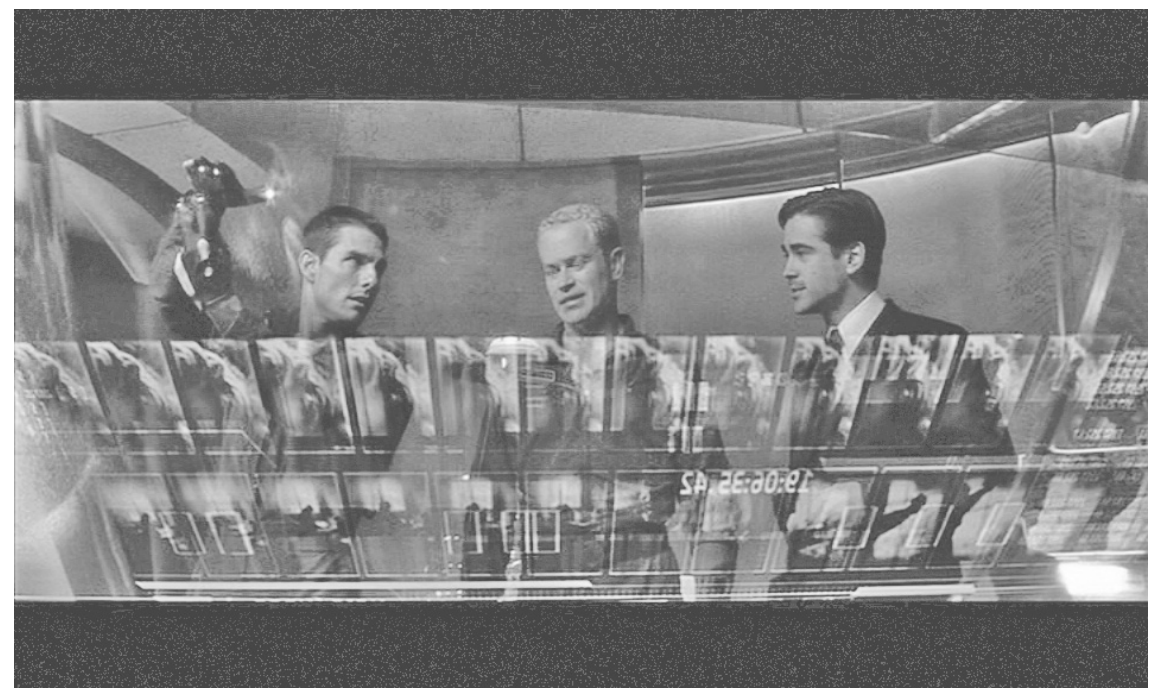


Een enorm voordeel is inderdaad de grotere beschikbaarheid van het materiaal (kwantitatieve kwestie), maar men moet ook kwalitatief leren omgaan met deze kwantiteit. Zo zal men altijd aanvullende bronnen moeten gebruiken om gegevens uit databases te interpreteren. Een goed voorbeeld hiervan is de bijdrage over sociale netwerken in Nederland in dit themanummer. Kortom: een digitale database met historische data is geen vervangende methode, maar een aanvullend analytisch instrument.

Het ontstaan van deze nieuwe analytische instrumenten moet in een ruimer kader worden geplaatst. Met het groeiende (kwantitatieve) onderzoek naar sociale netwerken, receptie en consumentisme verwijderen we ons steeds meer van de gecanoniseerde filmgeschiedenis en van de bestudering van film als tekst. Alles lijkt te draaien rond film als één van de mogelijke vrijetijdsbestedingen, of zelfs als consumptieartikel of commodity. Deze ontwikkeling is overigens niet volledig nieuw en valt te plaatsen in het verlengde van de zogenaamde nieuwe filmgeschiedenis (New Film History) van de jaren tachtig. Deze revisionistische filmgeschiedenis, typisch product van het 'New Historicism', vindt haar oorsprong in de legendarische FIAF-Conferentie van I978 die plaatsvond te Brighton en waar meer dan vijfhonderd 'primitieve' films werden bekeken en (her)ontdekt. Uiteindelijk heeft de nieuwe filmgeschiedenis een verschuiving van tekst naar context teweeggebracht, aangezien steeds meer aandacht ging naar vertoningsplekken, catalogi, advertenties, etc. om de (her)ontdekte en verloren films te duiden. Vaak bleek het bekijken van films zelf contraproductief. Of zoals Robert C. Allen en Douglas Gomery het in hun baanbrekende werk Film History: Theory and Practice (I985) formuleerden:

'It is true that for one narrow form of film historical inquiry prints of films are the only valid data. However, for broader (and more interesting) questions, we think, nonfilmic materials prove invaluable. For certain investigations, film viewing is really an inappropriate research method. ${ }^{\text {, } 4}$

Het boek van Allen \& Gomery werd verplichte leerstof voor hele generaties studenten filmstudies, ook in Nederland, en de sporen ervan komen we nog dagelijks tegen.

De niet-tekstuele onderzoeksmethode is dus geen uitvinding van de 2 Ie eeuw en is zeker niet zomaar te koppelen aan de beschikbaarheid van digitale instrumenten, zoals bovenbeschreven databases. Deze digitale instrumenten zouden echter wel kunnen bijdragen tot een minder speculatieve filmgeschiedschrijving en tot een verdere verschuiving van de kijkervaring (de bioscoopganger als spectator) naar de bestedingspatronen (de bioscoopganger als consumer). Het groeiende onderzoek naar receptie binnen filmstudies zou uiteindelijk tot een revolutie kunnen leiden, of althans tot een evolutie waar de mediumspecificiteit zo goed als verdwijnt en waar het bestaansrecht van filmstudies in 
het nauw wordt gedreven. Dit zou neerkomen op een doorgedreven aandacht voor de context (ten koste van de tekst) en het bestuderen van patronen en netwerken op lange termijn. Of dit zal leiden tot een verdere splitsing van filmstudies en cinemastudies of tot een volledige opslorping van filmstudies door sociale wetenschappen is moeilijk te voorspellen. Binnen dit themanummer komen in ieder geval beide richtingen nog voor, al helt het sterk over naar de contextuele kant. Mogelijk moet de filmgeschiedenis opnieuw uitvinden wat de waarde en bruikbaarheid van de tekst is, met de rekenschap van het erkennen van verschillende versies van eenzelfde film enerzijds en simpelweg de afwezigheid van een groot deel van films anderzijds. De nu nog voorzichtige initiatieven van filmarchieven om het filmisch erfgoed op DVD te zetten en te distribueren zouden, mits op grotere schaal ontwikkeld, de nieuwsgierigheid van de filmhistoricus dermate kunnen voeden dat de filmtekst opnieuw 'in the picture' komt, op een manier die kan wedijveren met de Brighton-conferentie die in de eerste plaats ging om het bekijken van oud en onbekend filmmateriaal.

\section{Inhoud van dit nummer}

Dit themanummer opent met de bijdrage van Robert Allen die een poging doet om de filmgeschiedenis te verbinden met de nieuwe discipline van de culturele geografie, een variant van de sociale geografie. Allen bespreekt de heterogene plek van cinema. Het gaat hem daarbij niet zozeer om de bioscooparchitectuur dan wel om het - veranderende - spectrum van de sociale context van de toeschouwer. Om de filmtoeschouwer op een juiste manier te positioneren is het nodig om diens bredere sociale context te reconstrueren. Daarom vindt Allen dat het tijd is om de 'plek' van de filmcultuur te (her)definiëren en maakt daarbij onderscheid tussen de letterlijke plaats (place) en de meer figuurlijke ruimte (space). Hij illustreert dit aan de hand van zijn eigen onderzoek naar de segregatie van ruimte in specifieke steden in het Zuiden van de Verenigde Staten; hij geeft daarbij aan dat als je alleen naar de filmprogramma's van dergelijke bioscopen zou kijken je een belangrijk deel van deze specifieke realiteit overslaat. Het gaat Allen meer om de filmervaring die te plaatsen is in een groter geheel. Vandaar ook zijn pleidooi voor sociale geschiedenis op lokaal en regionaal vlak.

Het artikel van Fransje de Jong, Thunnis van Oort, Clara Pafort-Overduin en André van der Velden laat zien hoe in Nederland contextueel én tekstueel filmhistorisch onderzoek wordt beoefend. Met dit onderzoek tasten ze expliciet de grenzen van een digitale database zoals Cinema Context af. In de eerste plaats beschrijven ze de niet-bioscopische filmvertoning in Limburg (officierenclubs) en de fricties en assimilaties van dit circuit met de gewone bioscoopwereld. Vervolgens buigen ze zich over de identiteit van joodse bioscoopondernemers zowel gezien vanuit de ogen van de joden zelf als vanuit de ogen van hun tegenstanders - om zo uiteenlopende discursieve praktijken te traceren. Tot slot pro- 
beren ze het succes en falen van individuele Jordaanfilms te verklaren vanuit de mogelijkheden van 'female upward mobility' in de in de films gerepresenteerde cabarets. Via een microgeschiedenis op vertoningsgebied en onderzoek naar de identiteit van een beroepsgroep voert het artikel naar een kwestie die je nationaal zou kunnen noemen en te maken heeft met representatie en identificatie. De onderwerpen hebben alledrie een band met het artikel van Robert Allen wat betreft de 'vertoningsplek' (of 'venue' zoals genoemd in het kader van het London Project) als onderdeel van een groter verband of 'space', wat betreft segregatie en emancipatie in de film- en bioscoopwereld. De onderzochte 'plekken' zijn belangrijk voor onderzoek naar sociale netwerken, niet alleen op contextueel (of reëel) vlak, maar ook wat betreft de tekst of representatie.

Het artikel van Karel Dibbets sluit direct aan bij de bespreking van het onderzoek van Pafort, in zoverre dat het ook een nationale dimensie heeft en gericht is op representatie, maar het heeft duidelijk een omgekeerde doelstelling. Via de - gecoupeerde of afwezige - tekst wordt een verklaring gezocht voor het gebrek aan populariteit van het medium film in Nederland. In de Europese context is Nederland inderdaad een buitenbeentje als het op bioscoopcultuur aan komt. Dibbets zoekt hiervoor een gewaagde maar interessante verklaring in de Nederlandse verzuiling. Deze zou namelijk de niet-verzuilde bioscoop hebben 'gedwongen' om de representatie van diezelfde verzuiling in het filmaanbod buiten beeld te houden, wat leidde tot censuur bij buitenlandse films en zelfcensuur bij Nederlandse producties. Dibbets noemt het de 'AVRo'-cultuur maar je zou het ook de Polygoonjournaalmentaliteit kunnen noemen: vooral niemand voor het hoofd stoten. In meer algemene zin gaat het artikel over de relatie tussen vraag en aanbod in de filmcultuur, over de receptie van films door zuilen en filmkeuring, en over een taboe in de receptie van film in Nederland. Dibbets verwijst hierbij naar grotere verbanden en structuren die in de filmcultuur zijn ingeweven en die misschien de 'andere' receptie in dit land kunnen verklaren. De receptieproblematiek vormt met andere worden de basis van zijn artikel.

$\mathrm{Na}$ deze regionale en nationale geschiedschrijving wordt de tweede helft van het nummer gevormd door meer theoretische (of zelfs polemische) artikelen over de historiografische onderzoeksmethode(s). Dit tweede luik opent met de tekst van Ian Christie, die pleit voor een geschiedschrijving waarbij het factuele voorop staat: 'Just the facts, ma'am'. Dit empiristische pleidooi staaft hij vooraleerst met een historiografisch overzicht. Hij roemt daarbij het werk van vergeten of verguisde pioniers als Georges Sadoul (Histoire générale du cinéma) en Rachael Low (The History of the British Film). Daarna onderstreept Christie het belang van de voorhoede van de 'Early Cinema Movement', als ook van het technologisch onderzoek van Barry Salt (Film Style and Technology) en het stilistisch onderzoek van David Bordwell, Janet Staiger en Kristin Thompson (The Classical Hollywood Cinema). Wat hierbij duidelijk wordt is dat ook de filmtekst kan worden onderworpen aan een kwantitatieve analyse. Salt deed het met zijn average shot length (ASL), tegenwoordig hebben we de Cinematics-site van Yuri 
Tsivian. Christie is ten slotte de leider van het bovengenoemde London Project waarin de Londense distributie en vertoning voor de vroegste jaren systematisch en digitaal wordt ontsloten.

Daar waar Christie wijst op de verdiensten van de New Film History, rekent Richard Maltby af met deze filmhistoriografische beweging die sinds de jaren tachtig de filmgeschiedenis domineert en die weliswaar heeft gezorgd voor een verschuiving van tekst naar context, maar tegelijkertijd niet ver genoeg is gegaan. Maltby schetst de recente discussies over het status van de filmgeschiedenis en bespreekt hierbij de standpunten van verschillende prominente filmwetenschappers (zoals Janes Gaines, Barbara Klinger, Philip Rosen, Vivian Sobchack, Michèle Lagny, Richard Abel en Toby Miller). Vervolgens doet hij een oproep tot onderzoek naar consumentisme. Hij betoogt dat de filmgeschiedschrijving zich moet plaatsen in (of schikken naar) de algemene tendensen van de hedendaagse geschiedschrijving en daarom rekening moet houden met de poststructuralistische kritiek van geschiedenis als een realistische fictie. Filmstudies zou zich nog meer en explicieter moeten bezighouden met het publiek dan met de films. Hierbij moet het publiek opnieuw worden gedefinieerd. Voor Maltby is de bioscoopganger in de eerste plaats een consument. Centraal staat dus de vraag naar de receptie als bestedingspatroon en naar de condities van het dagelijkse leven (vergelijkbaar met het onderzoek van het London Project: 'How to spend a penny?'), eerder dan naar de filmesthetische ervaring.

Jean-Jacques Meusy, ten slotte, analyseert de huidige stand van het filmhistorische onderzoek in Frankrijk. Hij gaat vooral in op de problematiek van de lokale en regionale filmgeschiedschrijving die typerend is voor de Franse situatie. Zijn relaas is met enig voorbehoud breder (dit wil zeggen: internationaal) te projecteren. Het staat vast dat veel resultaten van onderzoek, of dat nu door amateurs of studenten gebeurt, nauwelijks vrijelijk beschikbaar zijn, waardoor we veel data missen. Of deze data waardevol zijn, hangt uiteraard sterk af van de wetenschappelijke rigeur waarmee deze lokale en regionale onderzoeken zijn uitgevoerd. Feit blijft dat ze nauwelijks of zeer moeilijk te raadplegen zijn. Meusy geeft de schuld deels aan de lakse overheid, deels aan de filmwetenschap zoals die beoefend wordt aan de Franse universiteiten: deze is nog altijd sterk tekstgeoriënteerd en plaatst filmgeschiedenis laag in de hiërarchie. Meusy besluit zijn tekst met een oproep tot het beschikbaar maken van materiaal en met de meer utopische visie dat het onderhand tijd wordt om de diverse microgeschiedenissen samen te voegen om zo tot een nieuwe macrogeschiedenis te komen.

Of deze nieuwe macrogeschiedenis verder moet gaan dan een totaliserende filmgeschiedenis à la Sadoul en uiteindelijk zal leiden tot het einde van de filmgeschiedenis als zelfstandige discipline, wordt voorlopig in het midden gelaten. Op de conferentie 'Cinema in Context' is in ieder geval gebleken dat de welwillendheid tot uitwisseling van data en tot het opzetten van een uniforme database-structuur niet ontbreekt. De toekomst zal ons vertellen of dit zal uitgroeien tot een academische variant van de Im Db. 
Voor de medewerking aan dit nummer zijn wij dank verschuldigd aan de auteurs, in het bijzonder Karel Dibbets, aan de onderzoekers van de hierboven vermelde projecten en aan het Nederlands Filmmuseum.

\section{Noten}

I N. Finke, 'Do You Iм Dв? How a fanatic helped put Hollywood under one big tent', LA Weekly, 5 augustus 2004; http://www.laweekly.com/general/deadline-hollywood/do-you-imdb/9084/ (geraadpleegd op 28 oktober 2006). Het webadres van de Internet Movie Database is http://www. imdb.com/.

2 Het webadres van Cinema Context is http://www.cinemacontext.nl/.

3 Zie http://www.cccproject.com/main.htm (geraadpleegd op 28 oktober 2006).

4 Richard Maltby (Flinders University), Kate Bowles (University of Wollongong), Deb Verhoeven (RMIt University) en Mike Walsh (Flinders University) leiden het onderzoeksproject 'Regional Markets and Local Audiences: a History of Australian Cinema Consumption', ondersteund door de Australian Research Council. Het project combineert onderzoek naar de praktijken van filmdistributie en -vertoning met oral history onderzoek naar de ervaring van filmpubliek. Zie onder meer: http://apps.arc.gov.au/arcresearch/research/Detail.aspx?id=DP0560I44.

5 Eén van de Amerikaanse projecten die nu reeds on line is maar waar nog steeds aan wordt gewerkt, is het Williamsburg Theater Project van Arthur Knight en Robert Nelson, een database over alle films die ooit in de stad Williamsburg va zijn vertoond. Naast films kun je ook zien welke andere culturele activiteiten zich gelijktijdig afspeelden en welke algemene historische gebeurtenissen plaatsvonden. Lokale kranten zijn de bron voor de database. Zie: http://www.wm.edu/amst/ wtp/.

6 Zie http://www.homerproject.org/. Het onderzoeksverband werd in 2004 in Washington DC opgericht door de International Cinema Audiences Research Group (ICARP).

7 H. Birett, Das Filmangebot in Deutschland 1895-1911, München 1991; Verzeichnis in Deutschland gelaufener Filme 1911-1920, München 1980; Quellen zur Filmgeschichte (speziell zur Stummfilmzeit), http://www.kinematographie.de/. Het bronnenmateriaal van Birett bestaat uit zo'n 270 verschillende bronnen en is veel uitgebreider dan de I $\mathrm{m}$ D of een andere recente database van Duitse film: http://www.filmportal.de/. Het Siegenproject heeft de rechten van Biretts database gekocht en in een relationele database verwerkt. Zie ook: J. Garncarz \& M. Ross, 'Die Siegener Datenbanken zum frühen Film in Deutschland', KINtop, vol. I4/I5, 2006, p. I5I-I63.

8 Zie http://www.fk6r5.uni-siegen.de/neu/en/teilprojekteng.php?projekt=A5.

9 Zie http://www.wgfilmtv.ugent.be/wgfilm\&tvEn/research/the_enlighted_city.php, en http:// www.ua.ac.be $/$ main.aspx? $={ }^{*}$ CWONZ\&n $=39392 \& c t=40094 \& \mathrm{e}=9056 \mathrm{r}$. Overigens wordt in Gent ook gewerkt aan een systematisch onderzoek naar filmcensuur in Vlaanderen, onder de titel 'Verboden Beelden'. Zie: http://www.wgfilmtv.ugent.be/wgfilm\&tvnL/onderzoek/verboden_beelden.php.

Io Zie http://londonfilm.bbk.ac.uk/about/project/. Sommige vondsten van het London Project droegen bij aan de reizende tentoonstelling Moving Pictures Come to London: The First Decades, 1894-1914, die nu langs centra voor lokale geschiedenis en bibliotheken in Londen reist. In februari 2007 zal naar het voorbeeld van het Parijse Forum des Images de London Screen Study Collection worden geopend in het nieuwe Centre for Film and Visual Media Research van Birkbeck College, in Gordon Square, net achter Virginia Woolfs huis.

II I. Blom, Jean Desmet and the Early Dutch Film Trade, Amsterdam 2003, p. IO4; B.R. Mitchell, European Historical Statistics, 1750-1970, London/Basingstoke I975, p. 20, p. 76-78. 
I2 Zie http://www.xs4all.nl/ kd/. Deze database, getiteld Netherlands Cinema History, ging al in I999 online. Vervolgens heeft Dibbets de gegevens van Netherlands Cinema History opgenomen in de Cinema Context database.

I3 Ook dit werd op de conferentie 'Cinema in Context' gesuggereerd door Richard Maltby, die aan het einde van zijn eigen lezing tien jaar vooruit keek.

I4 R.C. Allen \& D. Gomery, Film History: Theory and Practice, New York I985, p. 38. Geciteerd in T. Elsaesser, 'The New Film History', Sight and Sound, vol. 55, n. 4, I986, p. 247. 